\title{
HIV-related neuropathy: current perspectives
}

\author{
This article was published in the following Dove Press journal: \\ HIVIAIDS - Research and Palliative Care \\ 10 September 2013 \\ Number of times this article has been viewed
}

\section{Sonja G Schütz \\ Jessica Robinson-Papp}

Department of Neurology, Mount Sinai School of Medicine, New York, NY, USA
Correspondence: Sonja G Schütz

Department of Neurology,

Mount Sinai School of Medicine,

One Gustave Levy Place, Box II 37,

New York, NY 10029, USA

$\mathrm{Tel}+|2| 224 \mid 7074$

Fax + I 2129877635

Email sonja.schuetz@mountsinai.org
Abstract: Distal symmetric polyneuropathy (DSP) related to human immunodeficiency virus (HIV) is one of the most common neurologic complications of HIV, possibly affecting as many as $50 \%$ of all individuals infected with HIV. Two potentially neurotoxic mechanisms have been proposed to play a crucial role in the pathogenesis of HIV DSP: neurotoxicity resulting from the virus and its products; as well as adverse neurotoxic effects of medications used in the treatment of HIV. Clinically, HIV DSP is characterized by a combination of signs and symptoms that include decreased deep tendon reflexes at the ankles and decreased sensation in the distal extremities as well as paresthesias, dysesthesias, and pain in a symmetric stocking-glove distribution. These symptoms are generally static or slowly progressive over time, and depending on the severity, may interfere significantly with the patient's daily activities. In addition to the clinical picture, nerve conduction studies and skin biopsies are often pursued to support the diagnosis of HIV DSP. Anticonvulsants, antidepressants, topical agents, and nonspecific analgesics may help relieve neuropathic pain. Specifically, gabapentin, lamotrigine, pregabalin, amitriptyline, duloxetine, and high-dose topical capsaicin patches have been used in research and clinical practice. Further research is needed to elucidate the pathogenesis of HIV DSP, thus facilitating the development of novel treatment strategies. This review discusses the epidemiology, pathophysiology, clinical findings, diagnosis, and management of DSP in the setting of HIV.

Keywords: neuropathy, human immunodeficiency virus, acquired immunodeficiency syndrome, AIDS, distal symmetric polyneuropathy, DSP, pain

\section{Introduction}

Human immunodeficiency virus (HIV) is a retrovirus that causes progressive failure of the immune system in humans. More than 34 million people are infected with HIV worldwide, and every year approximately 2.7 million new infections with the virus occur. ${ }^{1}$ Since the early descriptions of HIV, distal symmetric polyneuropathy (DSP) has been recognized as one of the common neurologic manifestations associated with advanced stages of HIV. ${ }^{2}$ With the introduction of combination antiretroviral therapy (cART) in 1996, the length of survival of individuals has dramatically improved. For many patients in resource-rich countries, HIV is no longer a rapidly progressive, fatal illness but rather a chronic condition. However, to this date, DSP remains one of the most common neurologic complications of HIV, and it is associated with significant morbidity. ${ }^{3-7}$

\section{Epidemiology: prevalence and incidence of HIV neuropathy}

Most estimates of the prevalence of HIV DSP in the cART-era range from $50 \%-60 \%$, although prevalence as low as $21 \%$ has been reported..$^{2,6,7}$ This variability can be in part 
attributed to the different definitions of HIV DSP, with some studies defining DSP as one clinical sign (ie, reduced ankle reflexes or reduced pinprick sensation or reduced vibration sensation in the feet), some requiring two clinical signs, and some using validated screening or diagnostic instruments. 7,43,49 DSP seems to be rare in children with HIV infection, ${ }^{8,9}$ but in an adult, pre-cART population, almost all patients had evidence of DSP on autopsy, even those without clinical signs and symptoms during their lifetime. ${ }^{10}$ The incidence of HIV DSP varies from 12-25 per 100 person-years. ${ }^{11,12}$ In patient populations on neurotoxic medication, particularly stavudine, the incidence tends to be at the higher end of that range. ${ }^{13}$ High doses of stavudine have been associated with a higher incidence of DSP than low doses. ${ }^{14}$

\section{Pathophysiology}

DSP has been recognized as a common complication of HIV since the late 1980s. Nonetheless, studies investigating the macroscopic and microscopic features of HIV DSP in humans are scarce, and many of them are limited by small sample sizes as well as lack of control groups and clinical correlates. In humans, the pathologic hallmarks of HIV neuropathy include distal axonal degeneration, neuronal loss in dorsal root ganglia (DRG) of affected nerves, inflammatory cell infiltration, and reduced epidermal nerve fiber (EDNF) density. ${ }^{10,15}$

The pathogenesis of HIV DSP in humans is not completely understood, but there are several promising hypotheses. Two distinct pathophysiologic processes are thought to contribute to the development of HIV DSP: direct neurotoxicity of the virus and its products and neurotoxicity of cART medications. Both processes will be discussed below. For a more detailed review of pathogenesis, see Kamerman et al. ${ }^{16}$

\section{Neurotoxic effects of HIV}

Two mechanisms of HIV neurotoxicity have been proposed: direct neurotoxicity through infection of neurons with the HIV, and indirect neurotoxicity through viral gene products and/ or activation of an inflammatory response to HIV. While it remains controversial whether HIV can enter neurons and thus be directly neurotoxic, ${ }^{17}$ there is growing evidence supporting the indirect neurotoxicity of HIV through inflammation and viral proteins. Several proteins such as trans-activator of transcription, negative regulatory factor (Nef), stromal cell-derived factor 1-alpha, and regulated upon activation, normal $\mathrm{T}$ cell expressed and secreted (RANTES) have been implicated in the development of HIV-related central nervous system disease, including HIV-associated neurocognitive impairment.
The strongest evidence for indirect neurotoxic effects of HIV on the peripheral nervous system stems from research investigating the role of glycoprotein (gp)120. Gp120 is a well-studied glycoprotein exposed on the surface of the HIV envelope, and its involvement in the pathogenesis of HIV DSP has been shown using in vitro and in vivo models. In vitro, gp120 can induce neuronal cell lysis in cultured DRG cells. ${ }^{18}$ Furthermore, gp120 activates macrophages, which in turn release neurotoxic inflammatory mediators such as tumor necrosis factor-alpha and interleukin-1. ${ }^{19}$ Similarly, gp120 has been shown to induce Schwann cells to release RANTES, which causes dorsal root ganglion neurons to produce tumor necrosis factor-alpha, leading to neuronal cell death through tumor necrosis factor receptor 1 -mediated neurotoxicity. ${ }^{20}$ In vivo, the application of gp 120 to the sciatic nerve in rats leads to neuronal swelling ${ }^{21}$ and macrophage infiltration, ${ }^{22}$ similar to inflammatory processes observed in patients with HIV ${ }^{23}$ In a behavior model of pain, rats exposed to gp120 develop hypernociception, which can persist for weeks after a single application of gp120. . $^{21,22}$

Additionally, there is evidence that mitochondrial DNA damage is more pronounced in patients with HIV DSP compared to HIV patients without DSP and to HIV-negative controls. In patients with HIV DSP, the degree of mitochondrial DNA damage is higher in the distal sural nerve than in the proximally located DRG. ${ }^{25}$ This spatial distribution suggests that mitochondrial dysfunction may contribute to the clinical phenotype of length-dependent neuropathy.

\section{Neurotoxic effects of cART}

Nucleoside analog reverse-transcriptase inhibitors (NRTIs) such as didanosine, zalcitabine, and stavudine have been shown to be associated with DSP. ${ }^{26-29}$ While the use of these NRTIs has significantly declined over the past decade, they continue to be part of the mainstay of HIV therapy in resource-poor countries, particularly stavudine. Symptomatic DSP due to NRTIs is cited as a reason for a change in HIV treatment regimens, as symptoms may improve after discontinuation of the offending drug. ${ }^{30,31}$

DSPs originating from HIV or NRTIs are clinically indistinguishable from one another. Nonetheless, different pathophysiologic mechanisms have been implicated in the development of the clinical phenotype. One hypothesis is that NRTIs lead to mitochondrial dysfunction through inhibition of mitochondrial DNA polymerase gamma, ${ }^{32,33}$ which was first demonstrated in vitro using PC-12 cells. ${ }^{34} \mathrm{HIV}$-positive patients on zalcitabine were found to have enlarged vacuolated mitochondria depleted of DNA. ${ }^{35}$ In DRG cultures, 
didanosine has been shown to cause cell death. ${ }^{36}$ In vivo, exposure to zalictabine leads to reduced nerve conduction velocities and amplitudes as well as axonal cell loss in rabbits. ${ }^{37}$ In rats, NRTI exposure causes hypersensitivity of hind paws, dying-back of EDNFs, and macrophage infiltration into the DRG. ${ }^{38,39}$

\section{Synergistic neurotoxic effects of HIV and NRTIs}

There is evidence from animal studies that the combination of HIV and NRTIs may lead to an increased risk of pathological findings. For instance, transgenic mice expressing gp120, as well as wild-type mice exposed to didanosine, remain free of any pathology, but gp120-transgenic mice with didanosine exposure exhibit thermal hypersensitivity, loss of unmyelinated axons, and reduced EDNF densities. ${ }^{40}$ In humans, the incidence of HIV DSP is higher in patients treated with stavudine compared to those on other HIV medications. ${ }^{13}$

\section{Risk factors}

Before the introduction of cART, HIV neuropathy was closely associated with advanced immunosuppression, which is reflected in a lower CD4 count and a higher viral load. ${ }^{41}$ To this day, HIV neuropathy continues to be a predictor of death in patients of limited means living in resource-poor countries. $^{42}$

In patients treated with cART, age is the most important risk factor for DSP. ${ }^{3,7,26,27,43-48}$ Stavudine exposure is another risk factor that is frequently identified, ${ }^{7,46,48}$ whereas the relationship to other neurotoxic medications exposure is less clear. ${ }^{49}$ Several studies found an association with height ${ }^{26,44} 47$ and ethnicity, ${ }^{26,43}$ but these findings were not replicated by other investigators. ${ }^{49} \mathrm{CD} 4$ count in the cART-era does not seem to be related to neuropathy, ${ }^{43,50,51}$ but there are several studies suggesting that a lower CD4 nadir represents a risk factor for HIV neuropathy., ${ }^{3,27,44}$ Likewise, viral load is not related to HIV neuropathy. ${ }^{26,43,44,50-52}$ The results regarding coinfection with hepatitis $\mathrm{C}$ are conflicting, with most studies not finding a relationship between hepatitis $\mathrm{C}$ coinfection and DSP. ${ }^{44,53}$ One study showed higher rates of neuropathy in HIV patients who were coinfected with human T-lymphotropic virus type $2 .{ }^{54}$

Diabetes mellitus (DM) and alcohol abuse are known causes of peripheral neuropathy in the general population. In patients with HIV, DM increases the risk of DSP, ${ }^{43,44}$ but the results of studies regarding alcohol are inconsistent. ${ }^{6,43,44,50}$ Statin use has been shown to correlate with HIV DSP. ${ }^{44}$ Furthermore, substance abuse and the number of substances used were associated with a higher incidence of HIV DSP in a recent study. ${ }^{49}$ These results suggest that risk factors of peripheral neuropathy in the general population exacerbate the risk of DSP in HIV patients.

\section{Clinical presentation}

Neuropathy in HIV is a predominantly distal, symmetric, sensory neuropathy characterized by a variety of clinical signs and symptoms. The most commonly encountered clinical signs of HIV DSP are decreased or absent ankle jerks and decreased pinprick and vibration sensation involving the distal lower extremities. ${ }^{2,67,55-57}$ Weakness and atrophy of the extremities are rare. ${ }^{58}$ HIV DSP can be asymptomatic, but many patients experience numbness, tingling, or pain in a stocking-glove distribution. ${ }^{7,55,59}$ In general, the symptoms of HIV DSP are first observed in the distal lower extremities and may gradually affect more proximal areas. In advanced cases, upper extremities can be involved as well. Cramping, stabbing, aching, and burning sensations in the affected extremities have also been described. ${ }^{55,57}$ The clinical manifestations of HIV DSP tend to be relatively stable over time. Distal epidermal denervation has been shown to be associated with progression of DSP. ${ }^{51}$

\section{Diagnosis and differential diagnosis}

Diagnosis of HIV DSP remains clinically based on a combination of typical signs and symptoms in addition to a history of HIV infection and possibly NRTI exposure.

There is currently no gold standard for the diagnosis of HIV DSP, but several clinical tools have been developed to assess this condition in clinical practice and research. The most commonly used are the Total Neuropathy Score ${ }^{58}$ and the Brief Peripheral Neuropathy Screen. ${ }^{60}$

The total neuropathy score combines grading of sensory, motor, and autonomic symptoms, pin and vibration sensation, muscle strength, deep tendon reflexes, sural and peroneal amplitudes assessed by nerve conduction studies (NCS), and quantitative sensory testing of vibration sensation into a composite score, which correlates with the severity of neuropathy. Although originally validated in patients with diabetic neuropathy, ${ }^{58}$ it has been widely used in HIV neuropathy.

The Brief Peripheral Neuropathy Screen provides a quick and easy assessment of neuropathy at the bedside and does not require neurophysiologic testing. Its sensitivity and specificity compared to the total neuropathy score are 35\%-49\% and $88 \%-90 \%$, respectively, with a positive predictive value of $72 \% .51,55$ 
Use of NCS is not routinely necessary for the diagnosis of HIV DSP but may be useful to rule out other conditions. If obtained, NCS may reveal slowed conduction velocities and reduced sensory nerve action potentials. . $7,61,62^{2}$

Skin biopsy of affected areas may show decreased EDNF densities and swelling of the nerve terminals. ${ }^{63,64}$ The degree of pathologic changes correlates with clinical pain scores ${ }^{15,65}$ and may predict worsening of symptoms in the next $1-2$ years. ${ }^{66}$ EDNF has been shown to correlate with age, height, body mass index, and duration of neurotoxic therapy, ${ }^{67,68}$ and in some studies but not others, with CD4 count. ${ }^{15,65,67}$

In addition, quantitative sensory testing is mainly used in research settings to measure detection threshold for changes in heat, cool, vibration, and to determine pain threshold, which may be abnormal in patients with HIV neuropathy, ${ }^{59,69}$ and correlate with the degree of EDNF abnormalities found on skin biopsy. ${ }^{63,65}$ Abnormal results are not only found in peripheral nerve disorders but also in diseases affecting the central nervous system, which is why quantitative sensory testing is usually performed in conjunction with other studies to help differentiate between the two. ${ }^{70}$

Nerve biopsies are not routinely indicated for HIV DSP but may be considered in atypical cases, for example, those with rapid progression or with prominent motor involvement.

The differential diagnosis of HIV DSP includes other causes of peripheral neuropathy such as DM, vitamin B12 deficiency, renal or liver impairment, thyroid dysfunction, and monoclonal gammopathy. Laboratory tests to assess for these conditions are recommended so that adequate treatment can be initiated (Table 1).

\section{Treatment}

There is currently no US Food and Drug Administrationapproved treatment for HIV neuropathy. Several medications have been used off-label for symptomatic control of neuropathic pain, including anticonvulsants, topical treatments, antidepressants, and analgesics.

The rationale for the use of these medications is their proven benefit in treating neuropathic pain due to diabetic neuropathy and postherpatic neuralgia as outlined in the recommendations for the management of neuropathic pain by the International Association for the Study of Pain ${ }^{71}$ and guidelines for the treatment of diabetic neuropathy by the American Academy of Neurology. ${ }^{72}$ Of note, most of these agents have not been shown to be superior to placebo in clinical trials studying HIV DSP, which some authors attribute to a pronounced placebo effect in patients with HIV DSP. ${ }^{71}$
Commonly used medications include the anticonvulsants gabapentin, pregabalin, and lamotrigine; topical high-dose capsaicin patches; the antidepressants duloxetine and amitriptyline; and nonspecific analgesics such as nonsteroidal anti-inflammatory drugs, acetaminophen, and opioids (Table 2). In general, neuropathic pain remains difficult to treat, with only half of the treated population typically reporting a significant reduction in pain. ${ }^{73,74}$ Complete resolution of symptoms is rarely achieved; therefore, a reduction in symptom severity by $30 \%-50 \%$ may be a more realistic goal of therapeutic interventions. ${ }^{75}$

The following section provides an overview of clinical drug trials in HIV neuropathy.

A double-blind, randomized trial has shown that a single application of $8 \%$ capsaicin patch can alleviate pain for several weeks. ${ }^{76}$ Recently, a study comparing patients treated with a single 30-minute or 60-minute application of either high-dose (8\%) capsaicin or a low-dose $(0.04 \%)$ capsaicin revealed a trend toward greater pain reduction in the high-dose capsaicin group. This difference failed to reach statistical significance, which was attributed to a largerthan-expected reduction of pain in the subgroup of patients receiving the 60-minute application of low-dose capsaicin. ${ }^{77}$ In prior studies, low dose $(0.075 \%)$ capsaicin and lidocaine patches did not lead to improved pain control.78,79

Gabapentin reduced pain significantly and improved sleep in a small study with 24 patients. ${ }^{80}$ Lamotrigine provided some pain relief in a study of 227 patients with HIV DSP, especially in those patients who were treated with neurotoxic medications. ${ }^{81,82}$ A randomized, double-blind, placebocontrolled trial of pregabalin failed to demonstrate significant improvement of pain, but hyperalgesia was less pronounced in participants receiving pregabalin compared to placebo. ${ }^{83}$ Amitriptyline is frequently used in diabetic neuropathy; however, it appears to be less effective in HIV neuropathy based on two randomized, placebo-controlled studies. ${ }^{84,85}$

One small study showed that smoked cannabis improved pain more than identical placebo cigarettes; however, this benefit disappeared after 7 days. ${ }^{86} \mathrm{~A}$ short training program in self-hypnosis consisting of three weekly sessions was successful at reducing pain scores during a 7-week follow-up in a cohort of 36 patients with HIV DSP. ${ }^{87}$

A randomized, placebo-controlled trial of 250 patients investigating the effects of acupuncture did not show significant improvement of pain ${ }^{85}$ however, a newer study of 50 patients treated either with acupuncture plus moxibustion or a placebo procedure revealed a greater improvement of pain in the acupuncture/moxibustion group. ${ }^{88}$ 
Table I Laboratory studies in the initial evaluation of human immunodeficiency virus patients presenting with distal symmetric polyneuropathy

Basic metabolic panel

Liver function tests

Hemoglobin $A_{\text {Ic }}$

Vitamin BI2, folate

Thyroid function tests

Serum, urine protein electrophoresis and serum immunofixation

Hepatitis $C$ virus serology

Recently, several trials were conducted based on newer pathophysiologic models of HIV DSP. HIV commonly uses the $\mathrm{C}$-C chemokine receptor type 5 as a coreceptor to enter its target cells. Vicriviroc, a drug that binds to the $\mathrm{C}-\mathrm{C}$ chemokine receptor type 5 and prevents HIV from entering cells, and therefore thought to be able to interfere with the pathophysiologic mechanisms causing HIV DSP, did not improve pain compared to placebo in a trial of 118 patients with HIV DSP. ${ }^{89}$ A trial using prosaptide, a neurotrophic factor, was stopped at a planned futility analysis..$^{90}$ Acetyl-L-carnitine has been proposed as a booster of mitochondrial function, but it was unsuccessful in alleviating HIV DSP symptoms in a small open-label study involving 20 patients and in a randomized, placebo-controlled trial of 90 patients..$^{91,92}$ Although neurotrophic growth factor did lead to some improvement of DSP symptoms in an open-label study of 200 patients and a randomized placebo-controlled trial of 270 patients, it is associated with significant adverse effects at the injection sites, and it is currently not available clinically. ${ }^{93,94}$ Trials of memantine, mexilitine, and peptide $\mathrm{T}$ were unsuccessful. ${ }^{84,95,96}$

In terms of nonpharmacologic treatment options, a pilot study demonstrated improved pain score and sleep index scores after using bilateral night splints for three weeks in 22 patients with HIV neuropathy. ${ }^{97}$

Lastly, medical management of potentially contributing comorbid conditions, such as DM, vitamin deficiencies, and alcohol abuse, should be optimized.

\section{Other forms of neuropathy associated with HIV}

In addition to DSP, HIV can be associated with other disorders of the peripheral nervous system such as mononeuropathies, mononeuritis multiplex, inflammatory demyelinating polyneuropathy, progressive polyradiculopathy, and autonomic neuropathy. ${ }^{98-100}$

HIV-infected individuals, particularly those with DSP, may be at increased risk for superimposed mononeuropathies. The most common mononeuropathies include median neuropathy at the wrist (ie, carpal tunnel syndrome), ulnar neuropathy at the elbow, and peroneal neuropathy at the fibular head. Facial nerve palsy, often referred to as Bell's palsy, is commonly an idiopathic, presumably inflammatory condition. However, in the setting of HIV, particularly with advanced immunosuppression, other etiologies should be considered including varicella zoster virus, meningeal lymphomatosis, aseptic meningitis, syphilis, or tuberculosis. In such patients, a more comprehensive work-up may be warranted to distinguish these etiologies from idiopathic forms. ${ }^{101-103}$

Mononeuritis multiplex manifests as painful, progressive, sensory and motor deficits in multiple nerve distributions that may become confluent. It is a rare complication of HIV, and while the symptoms can be self-limited, a rapidly progressive variant caused by cytomegalovirus infection of peripheral nerves has been described in the setting of advanced immunosuppression. ${ }^{104-106}$

Two forms of inflammatory demyelinating polyneuropathy (IDP) have been described in HIV patients: an acute form of IDP, or Guillain-Barré syndrome, with rapidly progressive symptoms, and a chronic form characterized by slower progression or by a relapsing-remitting course. ${ }^{107}$ Clinically, both forms present with ascending muscle weakness and areflexia in addition to paresthesias. In HIV-negative patients with IDP, cerebrospinal fluid studies typically reveal albuminocytologic dissociation; that is, an elevated cerebrospinal fluid protein level in the absence of significant pleocytosis. In HIV-positive patients, a mild lymphocytic pleocytosis with elevated protein levels is commonly found in asymptomatic patients with high CD4 counts, ${ }^{108,109}$ and is therefore less specific for IDP in this patient population.

The clinical picture of polyradiculopathy is characterized by progressive sensory, motor, and reflex changes in a radicular distribution. In HIV patients, progressive polyradiculopathy may be secondary to infectious or neoplastic etiologies such as lymphoma, cytomegalovirus, treponema pallidum, or mycobacterium tuberculosis. ${ }^{110-113}$

Manifestations of autonomic neuropathy include orthostatic hypotension, gastroparesis, diarrhea and constipation, xerostomia, xerophthalmia, urinary incontinence, sexual dysfunction, sweating abnormalities, and sluggish pupillary

Table 2 Pharmacological treatment of neuropathic pain

Discontinuation of neurotoxic medication

Anticonvulsants: gabapentin, lamotrigine, pregabalin

Topical anesthetics: capsaicin, lidocaine

Antidepressants: duloxetine, amitriptyline

Analgesics: NSAIDs, acetaminophen, opioid analgesics

Abbreviation: NSAIDs, nonsteroidal anti-inflammatory drugs. 
reaction. ${ }^{114}$ Recent studies suggest that autonomic neuropathy is a common comorbidity of HIV DSP, affecting more than half of all HIV DSP patients and is associated with predictors of mortality as summarized by the Veterans Aging Cohort Study Index..$^{100,115,116}$

NCS and electromyography, cerebrospinal fluid studies, neuroimaging and autonomic function tests may be helpful to distinguish between HIV DSP and these other less common forms of neuropathy.

\section{Conclusion and future directions}

HIV DSP is the most common neurologic complication of HIV. Several mechanisms may be involved in the pathogenesis of HIV DSP such as neurotoxic effects of the virus and its gene products as well as neurotoxic medications used for the treatment of HIV. Clinically, HIV DSP is characterized by sensory symptoms such as dysethesias and paresthesias with symmetric involvement of the distal extremities. Signs of HIV DSP include decreased deep tendon reflexes and decreased sensation in a stocking-glove distribution. While the diagnosis of HIV DSP remains largely clinical, other conditions that lead to distal sensory neuropathies need to be excluded. The treatment of HIV DSP remains difficult. Topical medications such as high-dose capsaicin patches, and anticonvulsants have yielded the most promising results thus far. Additional research is needed to elucidate the mechanisms leading to HIV DSP, which in turn will allow for the development of targeted treatment strategies.

\section{Disclosure}

The authors report no conflicts of interest in this work.

\section{References}

1. World Health Organization. Global HIV/AIDS Response: Epidemic Update and Health Sector Progress Towards Universal Access: Progress Report 2011. Geneva: World Health Organization 2011. Available from: http://whqlibdoc.who.int/publications/2011/9789241502986_eng.pdf. Accessed May 12, 2013.

2. Tagliati M, Grinnell J, Godbold J, Simpson DM. Peripheral nerve function in HIV infection: clinical, electrophysiologic, and laboratory findings. Arch Neurol. 1999;56(1):84-89.

3. Ellis RJ, Rosario D, Clifford DB, et al; CHARTER Study Group. Continued high prevalence and adverse clinical impact of human immunodeficiency virus-associated sensory neuropathy in the era of combination antiretroviral therapy: the CHARTER Study. Arch Neurol. 2010;67(5):552-558.

4. Wiklund I, Holmstrom S, Stoker M, Wyrwich KW, Devine M. Are treatment benefits in neuropathic pain reflected in the Self Assessment of Treatment questionnaire? Health Qual Life Outcomes. 2013;11:8

5. Önen NF, Barrette EP, Shacham E, Taniguchi T, Donovan M, Overton ET. A review of opioid prescribing practices and associations with repeat opioid prescriptions in a contemporary outpatient HIV clinic. Pain Pract. 2012;12(6):440-448.
6. Luma HN, Tchaleu BC, Doualla MS, et al. HIV-associated sensory neuropathy in HIV-1 infected patients at the Douala General Hospital in Cameroon: a cross-sectional study. AIDS Res Ther. 2012;9(1):35.

7. Maritz J, Benatar M, Dave JA, et al. HIV neuropathy in South Africans: frequency, characteristics, and risk factors. Muscle Nerve. 2010;41(5):599-606.

8. Palmer M, Chersich M, Moultrie H, Kuhn L, Fairlie L, Meyers T. Frequency of stavudine substitution due to toxicity in children receiving antiretroviral treatment in sub-Saharan. AIDS. 2013;27(5): 781-785.

9. Govender R, Eley B, Walker K, Petersen R, Wilmshurst JM. Neurologic and neurobehavioral sequelae in children with human immunodeficiency virus (HIV-1) infection. J Child Neurol. 2011;26(11):1355-1364.

10. de la Monte SM, Gabuzda DH, Ho DD, et al. Peripheral neuropathy in the acquired immunodeficiency syndrome. Ann Neurol. 1988;23(5):485-492.

11. Mehta SA, Ahmed A, Laverty M, Holzman RS, Valentine F, Sivapalasingam S. Sex differences in the incidence of peripheral neuropathy among Kenyans initiating antiretroviral therapy. Clin Infect Dis. 2011;53(5):490-496.

12. Nakamoto BK, McMurtray A, Davis J, et al. Incident neuropathy in HIV-infected patients on HAART. AIDS Res Hum Retroviruses. 2010;26(7):759-765.

13. McGrath CJ, Njoroge J, John-Stewart GC, et al. Increased incidence of symptomatic peripheral neuropathy among adults receiving stavudine- versus zidovudine-based antiretroviral regimens in Kenya. J Neurovirol. 2012;18(3):200-204.

14. Pahuja M, Grobler A, Glesby MJ, et al. Effects of a reduced dose of stavudine on the incidence and severity of peripheral neuropathy in HIV-infected adults in South Africa. Antivir Ther (Lond). 2012;17(4):737-743.

15. Polydefkis M, Yiannoutsos CT, Cohen BA, et al. Reduced intraepidermal nerve fiber density in HIV-associated sensory neuropathy. Neurology. 2002;58(1):115-119.

16. Kamerman PR, Moss PJ, Weber J, Wallace VC, Rice AS, Huang W. Pathogenesis of HIV-associated sensory neuropathy: evidence from in vivo and in vitro experimental models. J Peripher Nerv Syst. 2012;17(1):19-31.

17. Kramer-Hämmerle S, Rothenaigner I, WolffH, Bell JE, Brack-Werner R. Cells of the central nervous system as targets and reservoirs of the human immunodeficiency virus. Virus Res. 2005;111(2):194-213.

18. Apostolski S, McAlarney T, Hays AP, Latov N. Complement dependent cytotoxicity of sensory ganglion neurons mediated by the gp 120 glycoprotein of HIV-1. Immunol Invest. 1994;23(1):47-52.

19. Jones G, Zhu Y, Silva C, et al. Peripheral nerve-derived HIV-1 is predominantly CCR5-dependent and causes neuronal degeneration and neuroinflammation. Virology. 2005;334(2):178-193.

20. Keswani SC, Polley M, Pardo CA, Griffin JW, McArthur JC, Hoke A. Schwann cell chemokine receptors mediate HIV-1 gp120 toxicity to sensory neurons. Ann Neurol. 2003;54(3):287-296.

21. Herzberg U, Sagen J. Peripheral nerve exposure to HIV viral envelope protein gp120 induces neuropathic pain and spinal gliosis. J Neuroimmunol. 2001;116(1):29-39.

22. Wallace VC, Blackbeard J, Pheby T, et al. Pharmacological, behavioural and mechanistic analysis of HIV-1 gp120 induced painful neuropathy. Pain. 2007;133(1-3):47-63

23. Nagano I, Shapshak P, Yoshioka M, Xin K, Nakamura S, Bradley WG. Increased NADPH-diaphorase reactivity and cytokine expression in dorsal root ganglia in acquired immunodeficiency syndrome. $J$ Neurol Sci. 1996;136(1-2):117-128.

24. Oh SB, Tran PB, Gillard SE, Hurley RW, Hammond DL, Miller RJ. Chemokines and glycoprotein 120 produce pain hypersensitivity by directly exciting primary nociceptive neurons. J Neurosci. 2001;21(14): 5027-5035.

25. Lehmann HC, Chen W, Borzan J, Mankowski JL, Höke A. Mitochondrial dysfunction in distal axons contributes to human immunodeficiency virus sensory neuropathy. Ann Neurol. 2011;69(1):100-110. 
26. Evans SR, Ellis RJ, Chen H, et al. Peripheral neuropathy in HIV: prevalence and risk factors. AIDS. 2011;25(7):919-928.

27. Holzinger ER, Hulgan T, Ellis RJ, et al; CHARTER Group. Mitochondrial DNA variation and HIV-associated sensory neuropathy in CHARTER. $J$ Neurovirol. 2012;18(6):511-520.

28. Menezes CN, Maskew M, Sanne I, Crowther NJ, Raal FJ. A longitudinal study of stavudine-associated toxicities in a large cohort of South African HIV infected subjects. BMC Infect Dis. 2011;11:244.

29. Oshinaike O, Akinbami A, Ojo O, et al. Influence of age and neurotoxic HAART use on frequency of HIV sensory neuropathy. AIDS Res Treat. 2012;2012:961510.

30. Woldemedhin B, Wabe NT. The reason for regimen change among HIV/AIDS patients initiated on first line highly active antiretroviral therapy in southern Ethiopia. NAm J Med Sci. 2012;4(1):19-23.

31. Phan V, Thai S, Choun K, Lynen L, van Griensven J. Incidence of treatment-limiting toxicity with stavudine-based antiretroviral therapy in Cambodia: a retrospective cohort study. PLOS ONE. 2012;7(1): e30647.

32. Estanislao L, Thomas D, Simpson D. HIV neuromuscular disease and mitochondrial function. Mitochondrion. 2004;4(2-3):131-139.

33. Kakuda TN. Pharmacology of nucleoside and nucleotide reverse transcriptase inhibitor-induced mitochondrial toxicity. Clin Ther. 2000;22(6):685-708.

34. Keilbaugh SA, Hobbs GA, Simpson MV. Effect of 2', $3^{\prime}$-dideoxycytidine on oxidative phosphorylation in the PC12 cell, a neuronal model. Biochem Pharmacol. 1997;53(10):1485-1492.

35. Dalakas MC, Semino-Mora C, Leon-Monzon M. Mitochondrial alterations with mitochondrial DNA depletion in the nerves of AIDS patients with peripheral neuropathy induced by $2^{\prime} 3^{\prime}$-dideoxycytidine (ddC). Lab Invest. 2001;81(11):1537-1544.

36. Bodner A, Toth PT, Miller RJ. Activation of c-Jun N-terminal kinase mediates gp120IIIB- and nucleoside analogue-induced sensory neuron toxicity. Exp Neurol. 2004;188(2):246-253.

37. Anderson TD, Davidovich A, Arceo R, Brosnan C, Arezzo J, Schaumburg H. Peripheral neuropathy induced by $2^{\prime}, 3^{\prime}$-dideoxycytidine. A rabbit model of $2^{\prime}, 3^{\prime}$-dideoxycytidine neurotoxicity. Lab Invest. 1992;66(1):63-74.

38. Joseph EK, Chen X, Khasar SG, Levine JD. Novel mechanism of enhanced nociception in a model of AIDS therapy-induced painful peripheral neuropathy in the rat. Pain. 2004;107(1-2):147-158.

39. Wallace VC, Blackbeard J, Segerdahl AR, et al. Characterization of rodent models of HIV-gp120 and anti-retroviral-associated neuropathic pain. Brain. 2007;130(Pt 10):2688-2702.

40. Keswani SC, Jack C, Zhou C, Höke A. Establishment of a rodent model of HIV-associated sensory neuropathy. J Neurosci. 2006;26(40): 10299-10304.

41. Childs EA, Lyles RH, Selnes OA, et al. Plasma viral load and CD4 lymphocytes predict HIV-associated dementia and sensory neuropathy. Neurology. 1999;52(3):607-613.

42. Birbeck GL, Kvalsund MP, Byers PA, et al. Neuropsychiatric and socioeconomic status impact antiretroviral adherence and mortality in rural Zambia. Am J Trop Med Hyg. 2011;85(4):782-789.

43. Anziska Y, Helzner EP, Crystal H, et al. The relationship between race and HIV-distal sensory polyneuropathy in a large cohort of US women J Neurol Sci. 2012;315(1-2):129-132.

44. Banerjee S, McCutchan JA, Ances BM, et al. Hypertriglyceridemia in combination antiretroviral-treated HIV-positive individuals: potentia impact on HIV sensory polyneuropathy. AIDS. 2011;25(2):F1-F6.

45. Wadley AL, Cherry CL, Price P, Kamerman PR. HIV neuropathy risk factors and symptom characterization in stavudine-exposed South Africans. J Pain Symptom Manage. 2011;41(4):700-706.

46. Cherry CL, Affandi JS, Imran D, et al. Age and height predict neuropathy risk in patients with HIV prescribed stavudine. Neurology. 2009;73(4):315-320.

47. Affandi JS, Price P, Imran D, Yunihastuti E, Djauzi S, Cherry CL. Can we predict neuropathy risk before stavudine prescription in a resourcelimited setting? AIDS Res Hum Retroviruses. 2008;24(10):1281-1284.
48. Smyth K, Affandi JS, McArthur JC, et al. Prevalence of and risk factors for HIV-associated neuropathy in Melbourne, Australia 1993-2006. HIV Med. 2007;8(6):367-373.

49. Robinson-Papp J, Gelman BB, Grant I, Singer E, Gensler G, Morgello S; National NeuroAIDS Tissue Consortium. Substance abuse increases the risk of neuropathy in an HIV-infected cohort. Muscle Nerve. 2012;45(4): $471-476$.

50. Morgello S, Estanislao L, Simpson D, et al; Manhattan HIV Brain Bank. HIV-associated distal sensory polyneuropathy in the era of highly active antiretroviral therapy: the Manhattan HIV Brain Bank. Arch Neurol. 2004;61(4):546-551.

51. Simpson DM, Kitch D, Evans SR, et al; ACTG A5117 Study Group. HIV neuropathy natural history cohort study: assessment measures and risk factors. Neurology. 2006;66(11):1679-1687.

52. Cherry CL, Skolasky RL, Lal L, et al. Antiretroviral use and other risks for HIV-associated neuropathies in an international cohort. Neurology. 2006;66(6):867-873.

53. Cherry CL, Affandi JS, Brew BJ, et al. Hepatitis C seropositivity is not a risk factor for sensory neuropathy among patients with HIV. Neurology. 2010;74(19):1538-1542.

54. Zehender G, Colasante C, Santambrogio S, et al. Increased risk of developing peripheral neuropathy in patients coinfected with HIV-1 and HTLV-2. J Acquir Immune Defic Syndr. 2002;31(4):440-447.

55. Ellis RJ, Evans SR, Clifford DB, et al; Neurological AIDS Research Consortium; AIDS Clinical Trials Group Study Teams A5001 and A362. Clinical validation of the NeuroScreen. J Neurovirol. 2005;11(6): 503-511.

56. Husstedt IW, Evers S, Reichelt D, et al. Screening for HIV-associated distal-symmetric polyneuropathy in CDC-classification stages 1, 2, and 3. Acta Neurol Scand. 2000;101(3):183-187.

57. Fuller GN, Jacobs JM, Guiloff RJ. Nature and incidence of peripheral nerve syndromes in HIV infection. $J$ Neurol Neurosurg Psychiatr. 1993;56(4):372-381.

58. Cornblath DR, Chaudhry V, Carter K, et al. Total neuropathy score: validation and reliability study. Neurology. 1999;53(8):1660-1664.

59. Martin C, Solders G, Sönnerborg A, Hansson P. Painful and non-painful neuropathy in HIV-infected patients: an analysis of somatosensory nerve function. Eur J Pain. 2003;7(1):23-31.

60. Cherry CL, Wesselingh SL, Lal L, McArthur JC. Evaluation of a clinical screening tool for HIV-associated sensory neuropathies. Neurology. 2005;65(11):1778-1781

61. Parry O, Mielke J, Latif AS, Ray S, Levy LF, Siziya S. Peripheral neuropathy in individuals with HIV infection in Zimbabwe. Acta Neurol Scand. 1997;96(4):218-222.

62. Smith T, Jakobsen J, Gaub J, Trojaborg W. Symptomatic polyneuropathy in human immunodeficiency virus antibody seropositive men with and without immune deficiency: a comparative electrophysiological study. J Neurol Neurosurg Psychiatr. 1990;53(12):1056-1059.

63. Herrmann DN, McDermott MP, Henderson D, Chen L, Akowuah K, Schifitto G; North East AIDS Dementia (NEAD) Consortium. Epidermal nerve fiber density, axonal swellings and QST as predictors of HIV distal sensory neuropathy. Muscle Nerve. 2004;29(3):420-427.

64. McCarthy BG, Hsieh ST, Stocks A, et al. Cutaneous innervation in sensory neuropathies: evaluation by skin biopsy. Neurology. 1995;45(10): $1848-1855$

65. Zhou L, Kitch DW, Evans SR, et al; NARC and ACTG A5117 Study Group. Correlates of epidermal nerve fiber densities in HIV-associated distal sensory polyneuropathy. Neurology. 2007;68(24):2113-2119.

66. Herrmann DN, McDermott MP, Sowden JE, et al. Is skin biopsy a predictor of transition to symptomatic HIV neuropathy? A longitudinal study. Neurology. 2006;66(6):857-861.

67. Shikuma C, Gerschenson M, Ananworanich J, et al; SEARCH 003 protocol team. Determinants of epidermal nerve fibre density in antiretroviralnaïve HIV-infected individuals. HIV Med. 2012;13(10):602-608.

68. Kokotis P, Schmelz M, Papadimas GK, et al. Polyneuropathy induced by HIV disease and antiretroviral therapy. Clin Neurophysiol. 2013;124(1): $176-182$. 
69. Bouhassira D, Attal N, Willer JC, Brasseur L. Painful and painless peripheral sensory neuropathies due to HIV infection: a comparison using quantitative sensory evaluation. Pain. 1999;80(1-2):265-272.

70. Sindrup SH, Gaist D, Johannsen L, et al. Diagnostic yield by testing small fiber function in patients examined for polyneuropathy. $J$ Peripher Nerv Syst. 2001;6(4):214-218.

71. Attal N, Finnerup N. Pharmacological management of neuropathic pain. [webpage on the Internet]. Seattle, WA: International Association for the Study of Pain. Pain: Clinical Updates. Nov 2010 (Volume XVIII, Issue 9). Available from: http://www.iasp-pain. org $/ \mathrm{AM} /$ Template.cfm? Section=Clinical_Updates\&Template $=/$ TaggedPage/TaggedPageDisplay.cfm\&TPLID $=5 \&$ ContentID=1566. Accessed June 7, 2013.

72. Bril V, England J, Franklin GM, et al; American Academy of Neurology; American Association of Neuromuscular and Electrodiagnostic Medicine; American Academy of Physical Medicine and Rehabilitation. Evidence-based guideline: treatment of painful diabetic neuropathy: report of the American Academy of Neurology, the American Association of Neuromuscular and Electrodiagnostic Medicine, and the American Academy of Physical Medicine and Rehabilitation. Neurology. 2011;76(20):1758-1765.

73. Raskin J, Pritchett YL, Wang F, et al. A double-blind, randomized multicenter trial comparing duloxetine with placebo in the management of diabetic peripheral neuropathic pain. Pain Med. 2005;6(5):346-356.

74. Lesser H, Sharma U, LaMoreaux L, Poole RM. Pregabalin relieves symptoms of painful diabetic neuropathy: a randomized controlled trial. Neurology. 2004;63(11):2104-2110.

75. Sindrup SH, Jensen TS. Efficacy of pharmacological treatments of neuropathic pain: an update and effect related to mechanism of drug action. Pain. 1999;83(3):389-400

76. Simpson DM, Brown S, Tobias J; NGX-4010 C107 Study Group. Controlled trial of high-concentration capsaicin patch for treatment of painful HIV neuropathy. Neurology. 2008;70(24):2305-2313.

77. Clifford DB, Simpson DM, Brown S, et al; NGX-4010 C119 Study Group. A randomized, double-blind, controlled study of NGX-4010, a capsaicin $8 \%$ dermal patch, for the treatment of painful HIVassociated distal sensory polyneuropathy. J Acquir Immune Defic Syndr. 2012;59(2):126-133.

78. Paice JA, Ferrans CE, Lashley FR, Shott S, Vizgirda V, Pitrak D. Topical capsaicin in the management of HIV-associated peripheral neuropathy. J Pain Symptom Manage. 2000;19(1):45-52.

79. Estanislao L, Carter K, McArthur J, Olney R, Simpson D; LidodermHIV Neuropathy Group. A randomized controlled trial of 5\% lidocaine gel for HIV-associated distal symmetric polyneuropathy. J Acquir Immune Defic Syndr. 2004;37(5):1584-1586.

80. Hahn K, Arendt G, Braun JS, et al; German Neuro-AIDS Working Group. A placebo-controlled trial of gabapentin for painful HIVassociated sensory neuropathies. J Neurol. 2004;251(10):1260-1266.

81. Simpson DM, Olney R, McArthur JC, Khan A, Godbold J, Ebel-Frommer K. A placebo-controlled trial of lamotrigine for painful HIV-associated neuropathy. Neurology. 2000;54(11):2115-2119.

82. Simpson DM, McArthur JC, Olney R, et al; Lamotrigine HIV Neuropathy Study Team. Lamotrigine for HIV-associated painful sensory neuropathies: a placebo-controlled trial. Neurology. 2003;60(9):1508-1514.

83. Simpson DM, Schifitto G, Clifford DB, et al; 1066 HIV Neuropathy Study Group. Pregabalin for painful HIV neuropathy: a randomized, doubleblind, placebo-controlled trial. Neurology. 2010;74(5):413-420.

84. Kieburtz K, Simpson D, Yiannoutsos C, et al. A randomized trial of amitriptyline and mexiletine for painful neuropathy in HIV infection. AIDS Clinical Trial Group 242 Protocol Team. Neurology. 1998;51(6): 1682-1688.

85. Shlay JC, Chaloner K, Max MB, et al. Acupuncture and amitriptyline for pain due to HIV-related peripheral neuropathy: a randomized controlled trial. Terry Beirn Community Programs for Clinical Research on AIDS. JAMA. 1998;280(18):1590-1595.
86. Abrams DI, Jay CA, Shade SB, et al. Cannabis in painful HIVassociated sensory neuropathy: a randomized placebo-controlled trial. Neurology. 2007;68(7):515-521.

87. Dorfman D, George MC, Schnur J, Simpson DM, Davidson G, Montgomery G. Hypnosis for treatment of HIV neuropathic pain: a preliminary report. Pain Med. Epub April 8, 2013.

88. Anastasi JK, Capili B, McMahon DJ, Scully C. Acu/Moxa for distal sensory peripheral neuropathy in HIV: a randomized control pilot study. J Assoc Nurses AIDS Care. 2013;24(3):268-275.

89. Yeh TM, Evans SR, Gulick RM, Clifford DB. Vicriviroc and peripheral neuropathy: results from AIDS Clinical Trials Group 5211. HIV Clin Trials. 2010;11(1):51-58.

90. Evans SR, Simpson DM, Kitch DW, et al; Neurologic AIDS Research Consortium; AIDS Clinical Trials Group. A randomized trial evaluating Prosaptide for HIV-associated sensory neuropathies: use of an electronic diary to record neuropathic pain. PLoS ONE. 2007;2(6):e551.

91. Osio M, Muscia F, Zampini L, et al. Acetyl-1-carnitine in the treatment of painful antiretroviral toxic neuropathy in human immunodeficiency virus patients: an open label study. J Peripher Nerv Syst. 2006;11(1):72-76.

92. Youle M, Osio M; ALCAR Study Group. A double-blind, parallelgroup, placebo-controlled, multicentre study of acetyl L-carnitine in the symptomatic treatment of antiretroviral toxic neuropathy in patients with HIV-1 infection. HIV Med. 2007;8(4):241-250.

93. Schifitto G, Yiannoutsos C, Simpson DM, et al; AIDS Clinical Trials Group Team 291. Long-term treatment with recombinant nerve growth factor for HIV-associated sensory neuropathy. Neurology. 2001;57(7):1313-1316.

94. McArthur JC, Yiannoutsos C, Simpson DM, et al. A phase II trial of nerve growth factor for sensory neuropathy associated with HIV infection. AIDS Clinical Trials Group Team 291. Neurology. 2000;54(5):1080-1088.

95. Schifitto G, Yiannoutsos CT, Simpson DM, et al; Adult AIDS Clinical Trials Group (ACTG) 301 Team. A placebo-controlled study of memantine for the treatment of human immunodeficiency virusassociated sensory neuropathy. J Neurovirol. 2006;12(4):328-331.

96. Simpson DM, Dorfman D, Olney RK, et al. Peptide T in the treatment of painful distal neuropathy associated with AIDS: results of a placebo-controlled trial. The Peptide T Neuropathy Study Group. Neurology. 1996;47(5):1254-1259.

97. Sandoval R, Runft B, Roddey T. Pilot study: does lower extremity night splinting assist in the management of painful peripheral neuropathy in the HIV/AIDS population? J Int Assoc Physicians AIDS Care (Chic). 2010;9(6):368-381.

98. Wulff EA, Wang AK, Simpson DM. HIV-associated peripheral neuropathy: epidemiology, pathophysiology and treatment. Drugs. 2000;59(6):1251-1260.

99. Robinson-Papp J, Simpson DM. Neuromuscular diseases associated with HIV-1 infection. Muscle Nerve. 2009;40(6):1043-1053.

100. Robinson-Papp J, Sharma S, Simpson DM, Morgello S. Autonomic dysfunction is common in HIV and associated with distal symmetric polyneuropathy. J Neurovirol. 2013;19(2):172-180.

101. Serrano P, Hernández N, Arroyo JA, de Llobet JM, Domingo P. Bilateral Bell palsy and acute HIV type 1 infection: report of 2 cases and review. Clin Infect Dis. 2007;44(6):e57-e61.

102. Bélec L, Gherardi R, Georges AJ, et al. Peripheral facial paralysis and HIV infection: report of four African cases and review of the literature. J Neurol. 1989;236(7):411-414.

103. Keane JR. Bilateral seventh nerve palsy: analysis of 43 cases and review of the literature. Neurology. 1994;44(7):1198-1202.

104. Simpson DM, Olney RK. Peripheral neuropathies associated with human immunodeficiency virus infection. Neurol Clin. 1992;10(3): 685-711.

105. Said G, Lacroix C, Chemouilli P, et al. Cytomegalovirus neuropathy in acquired immunodeficiency syndrome: a clinical and pathological study. Ann Neurol. 1991;29(2):139-146. 
106. Roullet E, Assuerus V, Gozlan J, et al. Cytomegalovirus multifocal neuropathy in AIDS: analysis of 15 consecutive cases. Neurology. 1994;44(11):2174-2182.

107. Cornblath DR, McArthur JC, Kennedy PG, Witte AS, Griffin JW. Inflammatory demyelinating peripheral neuropathies associated with human T-cell lymphotropic virus type III infection. Ann Neurol. 1987;21(1):32-40.

108. Gisslén M, Chiodi F, Fuchs D, et al. Markers of immune stimulation in the cerebrospinal fluid during HIV infection: a longitudinal study. Scand J Infect Dis. 1994;26(5):523-533.

109. Marshall DW, Brey RL, Cahill WT, Houk RW, Zajac RA, Boswell RN. Spectrum of cerebrospinal fluid findings in various stages of human immunodeficiency virus infection. Arch Neurol. 1988;45(9):954-958.

110. Silva CA, Oliveira AC, Vilas-Boas L, Fink MC, Pannuti CS, Vidal JE. Neurologic cytomegalovirus complications in patients with AIDS: retrospective review of 13 cases and review of the literature. Rev Inst Med Trop Sao Paulo. 2010;52(6):305-310.

111. Léger JM, Hénin D, Bélec L, et al. Lymphoma-induced polyradiculopathy in AIDS: two cases. J Neurol. 1992;239(3):132-134.
112. Hernández-Albújar S, Arribas JR, Royo A, González-García JJ, Peña JM, Vázquez JJ. Tuberculous radiculomyelitis complicating tuberculous meningitis: case report and review. Clin Infect Dis. 2000; 30(6):915-921.

113. Winston A, Marriott D, Brew B. Early syphilis presenting as a painful polyradiculopathy in an HIV positive individual. Sex Transm Infect. 2005;81(2):133-134.

114. Suarez GA, Opfer-Gehrking TL, Offord KP, Atkinson EJ, O’Brien PC, Low PA. The autonomic symptom profile: a new instrument to assess autonomic symptoms. Neurology. 1999;52(3):523-528.

115. Robinson-Papp J and Sharma S. Autonomic neuropathy in HIV is unrecognized and associated with medical morbidity. AIDS Patient Care STDS. In press 2013.

116. Justice AC et al. Toward a combined prognostic index for survival in HIV infection: the role of "non-HIV" biomarkers. HIV Med. 2010; 11:143-151.
HIV/AIDS - Research and Palliative Care

\section{Publish your work in this journal}

HIV/AIDS - Research and Palliative Care is an international, peerreviewed open-access journal focusing on advances in research in HIV, its clinical progression and management options including antiviral treatment, palliative care and public healthcare policies to control viral spread. The journal welcomes original research, basic science,

\section{Dovepress}

clinical \& epidemiological studies, reviews \& evaluations, expert opinion \& commentary, case reports \& extended reports. The manuscript management system is completely online and includes a very quick and fair peer-review system. Visit http://www.dovepress.com/ testimonials.php to read real quotes from published authors.

\footnotetext{
Submit your manuscript here: http://www.dovepress.com/hivaids---research-and-palliative-care-journal
} 